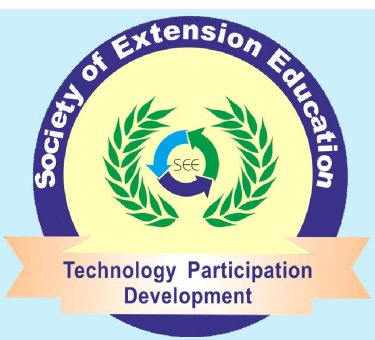

Research Article

\section{Indian Research Journal of Extension Education}

ISSN: 0972-2181 (Print), 0976-1071 (Online)

NAAS Rating : 5.22

Journal homepage: seea.org.in

https://doi.org/10.54986/irjee/2022/jan_mar/86-91

\title{
Traditional Piscicidal Knowledge along the Chakpi River and other Water Bodies in Chandel District, Manipur State : Past and Present Scenario
}

\author{
Kangjam Sonamani Singh ${ }^{1}$ and Athokpam Haribhushan ${ }^{2}$ \\ 1. SMS, Krishi Vigyan Kendra, Chandel, Manipur and 2.SMS. Krishi Vigyan Kendra, South Garo Hills, Meghalaya \\ Corresponding author e-mail : sonamanisingh@gmail.com
}

Paper Received on August 13, 2021, Accepted on November 02, 2021 and Published Online on January 01, 2022

\begin{abstract}
The present study was undertaken with an aim to expound the various indigenous technical knowledge (ITK) practices centring around the stagnant or semi-stagnant water bodies in Chandel district of Manipur. The prevailing indigenous practices were considered and only three groups of indigenous practices were found to be rational in the present scenario which could be further assessed, documented and propagated for the benefit of farming community. The three group of indigenous practices involve the age-old methods of stupefying the fish in ponds or rivers using tree barks, roots and leaves of specific trees or plants having ichthyotoxic properties. Two filters were applied to identify the ITKs. The first filter being rationality therein only ITK practices having rationality score more than 2.4 being explained in the study. The second filter was mean perceived effectiveness index (MPEI). Of the 17 practices evaluated, 3 were rational (42.08\%) while the remaining 14 were rejected as irrational (57.92\%). The perceived effectiveness and adoption rate analysis of these age-old ITKs indicated that, the traditional use of stupefying barks was rated as rational (3.01), perceived as highly effective (2.60) and adopted by 78 per cent of the respondents whereas on the lower end, the method incorporating the juice extract of ichthyotoxic leaves was rated as rational (2.48), perceived as effective (1.9) and adopted by 48 per cent of respondents.
\end{abstract}

Key words : Water bodies; Indigenous traditional knowledge; Ichthyotoxic plants.

$\mathbf{C}_{\text {handel district is located in the south-eastern }}$ part of Manipur (India) and it experiences hot summer and cold winter. Annual mean temperature surpasses 22ÚC and temperature during summer ranges from 35 to 46 ÚC. There is a mean yearly rainfall altering from 2000 to $2400 \mathrm{~mm}$. The vegetation is outweighed by pine including woody and herbaceous species. The geographical area of the Chandel district is $521 \mathrm{sq} . \mathrm{km}$ with 2.22 per cent of the total geographical area of the state. The total population is 168,217 (Census, 2011). Chandel has the lowest literacy rate in the state. As per the census of 2001, only 56 per cent of total population is literate of which 64 per cent are male. Average literacy rate in the state of Manipur is 80.3 per cent for male and 60.5 per cent for women.

The district of Chandel has three major rivers viz, the Maha, the Chakpi and the Lokchao and a major chunk of fishing activities centre around these three. The district borders Myanmar and is considered a hotspot blessed with diversified fish fauna.

Fish is one of the staple food items in the district and the local tribal fishermen have been using a rich 
and vast Indigenous Traditional Knowledge (ITK) in fish capture since centuries. These age-old traditional methods and practices have been practiced from time immemorial and though mostly primitive were quite sufficient to sustain the needs of local consumption. A majority of these indigenous methods centres around a lot of plants, which are significantly used as fish sedatives by local people in the aquatic resources of the region have been used since generations in the district.

Generally, the poor tribal fishermen of the district are involved in active fishing activities in and around the rivers and streams of the district. Even though mostly illiterate, these fishermen possess rich indigenous technical knowledge and expertise in fishing activities which they transfer from generations to generations. The different obstacles in their home situation, farming situation and social situation compel them to use their own wisdom for resolving the problem (Pradhan, 2015). Indigenous knowledge (IK) is the local knowledge knowledge that is unique to a given culture or society and it contrasts with the international knowledge system generated by universities, research institutions and private firms. It is the basis for local-level decision making in agriculture, health care, food preparation, education, natural-resource management, and a host of other activities in rural communities (Warren, 1991).

Traditional environmental knowledge gained international recognition through such documents as the World Conservation Strategy and Our Common Future. Both reports emphasized the need to use directly the environmental expertise of local people in managing natural resources (Shyam et al, 2013).

Indigenous knowledge incorporates local technologies but also cultural, social and economic aspects. Contextually, people-environment interaction shaped IK in which the environment consists of complex conditions shaped by factors such as the physical and biological environment, economic conditions such as market prices, operating costs, cost of production inputs, and socio-cultural conditions such as wishes and demands of formal and informal institutions, and cultural norms5. In response to these conditions the stakeholder undertakes actions. In the case of fisher folk these actions relates to decisions such as where to fish and when, equipment purchases, and marketing strategies.

The methods used in the district are results of experiences gained over time and are related to the topography of the fishing ground, Eco morphology and behaviour of the fish (Wanglar Alphonsa and Singh, 2017). Some of these methods, though primitive is quite effective in catching the fish in the otherwise slippery hill streams with fast flow of water. It is reported that a variety of plants having fish poisoning properties has been known for centuries.

Similarly, various plants used as ichthyotoxins in California, America and indeed on the continents in the temperate areas of the world (Kritzon, 2003). Different ichthyotoxic plants were used for fish poisoning in different villages and districts of Garhwal division. Leaves of Agave americana, Juglans regia and Sapium insigne are crushed and the pest was directly employed in the stagnant water of stream and rivers (Badola and Badola, 1999). While, leaf extract of locally available cactus rambans and crushed seed of Madhuca sp is very popular for fish toxicants in the pools and riffles of Champawat district of Kumaon Region (Joshi, 2004). Similarly, Northern Guyana natives used leaves and stem of Euphorbia cotinifolia L. and Phyllanthus brasiliensis (Aubl.) containing triterpene for poison of small fish in a stream (Van Andel, 2000).

Smartweed (Polygonum hydropiper, Linn.) used as fish toxicant by the tribal people of Karbi- Anglong district of Assam for catching fish from natural aquatic resources as well as for removal of uneconomical fishes from the aquaculture pond (Kalita et al, 2007). Similarly, various toxic plants (Aesculus indica, Sapindus mukorossi, Lyonia ovalifolia, and Zanthoxylum alatum) and their parts were used for fish poisoning in Alaknanda river and its tributaries in Garhwal Himalaya (Bahuguna et al, 2005).

\section{METHODOLOGY}

This study was conducted in Chandel district of Manipur, where a huge population of tribal folks undertakes either full-time or part-time fishery activities. They have been able to sustain themselves with fairly good catch using their traditional technical knowledge which have trickled down from generation to generation to harvest fish in the local water bodies. Two blocks from the selected district and three villages from each selected block were considered for data collection. Thus, a total of six villages and 180 tribal households were selected for identification and documentation of practices pertaining to fishing activities in the water bodies as 
ITKs. The validation of ITKs was carried out through rationality index and Mean Perceived Effectiveness Index (MPEI) of ITKs.

After documenting the various indigenous practices from the elderly farmers, a questionnaire comprising of the constructed practices were sent to the villages to assess the present knowledge and adoptability of these ITKs. The rationality assessment of these indigenous technologies was done by using the scoring procedure which was also used by Venkatesan and Sundaramari (2014) with little modifications. The response from the 180 households were tabulated after scores from one to four to each ITK were assigned based on their assessment of present rationality (Table 1). The rationality of each ITK was calculated considering the total and mean scores assigned to individual ITK practices. Thereafter, the ITKs were classified into two categories i.e. rational (mean score e"2.5) and irrational (mean score $<2.5$ ). After determination of rationality of ITKs, their adoption and perceived effectiveness were further analyzed using systematic interviews and questionnaires.

Table 1. Scores allotted after assessment of the rationality of the traditional practices

\begin{tabular}{lr}
\hline Responses & Scores \\
\hline Rational based on evidence from personal experience & 4 \\
Rational based on logical thinking derived from & 3 \\
environmental concern & \\
Irrational based on logical thinking of present scanario & 2 \\
Irrational based on diminishing returns & 1 \\
\hline
\end{tabular}

To find out the degree of adoption of ITK practices among the non-sample respondents in the study area, thirty tribal farmers were selected to calculate adoption index and it was measured in two-point continuum whether they had adopted the ITKs or not. The scores awarded by all respondents for a particular ITK were summed up to work out adoption index of a particular ITK practice through following formulae (Sundaramari and Ranganathan, 2003).

\section{$\mathrm{AI}=$ Adoption Index}

The overall perceived effectiveness of ITKs is defined as the extent or degree to which the farmers perceive that a positive outcome is obtainable by applying the ITKs in solving the problems (Sundaramari and Ranganathan, 2003). The perceived effectiveness of the rational ITKs was measured by using the MPEI procedure developed and used by Venkatesan and Sundaramari (2014) with slight rectifications. Table 2 shows the five attributes of the MPEI with their relevancy weightage.

Table 2. Inventory of 5 traits with their relevancy weightage

\begin{tabular}{lc}
\hline Traits & Relevancy weights \\
\hline Efficacy & 0.86 \\
Cost effectiveness & 0.81 \\
Residual health hazards & 0.77 \\
Local availability & 0.63 \\
Ease in preparation & 0.61 \\
\hline
\end{tabular}

The response of the tribal farmers was recorded in the form of rating of each ITK on three-point continuum (Agree-3, Undecided-2, Disagree-1) based on the above traits. If $\mathrm{R}_{1}, \mathrm{R}_{2}, \mathrm{R}_{3}, \ldots \mathrm{R} 5$ were to be the relevancy a weight of the five traits, and thereafter the Perceived Effectiveness index (PEI) was calculated as follows-

$$
\text { PEI }=\frac{W_{1} R_{1}+W_{2} R_{2}+W_{3} R_{3}+W_{4} R_{4}+W_{5} R_{5}}{R_{1}+R_{2}+R_{3}+R_{4}+R_{5}}
$$

$\mathrm{W}_{1}, \mathrm{~W}_{2} \ldots \mathrm{W}_{5}$ being the scores obtained for the traits for a specific ITK for a respondent. To determine the MPEI for a specific ITK, the mean score of PEIs acquired from each one of the respondents for a specific ITK were calculated. Hence, those ITKs which were having the MPEI value between 2 to 2.5 were deliberated as effective ITKs and MPEI of 2.5 and above were considered as highly effective.

\section{RESULTS AND DISCUSSION}

A wide range of ITKs related to fish harvesting were taken into consideration out of which only three group of ITK practices were found to be rational and considered as valid ITKs. All the ITKs were properly scored and their relevance in the present scenario and the generation analyzed.

It is evident from Table 3 that independent variables "sustainable income from fishing activities" and "attitude towards environmental concern" had positive and significant association with the adoptive behavior of the respondents at 1 per cent level of probability. This reveals that the respondents having good supportive income and attitude will exhibit higher level of practicing the traditional and environmental piscicidal techniques. It was also revealed that independent variables viz., 
Table 3. Association between independent variables and adoption behaviour of the respondents

\begin{tabular}{ll}
\hline Independent variables & $(\mathrm{r})$ \\
\hline Age & $-0.10218^{\mathrm{NS}}$ \\
Family size & $0.22659^{*}$ \\
Education & $0.11002^{\mathrm{NS}}$ \\
Size of landholding & $0.19308^{*}$ \\
Distance from the water bodies & $0.15604^{\mathrm{NS}}$ \\
Annual income & $0.20970^{*}$ \\
Sustainable income from fishing activities & $0.28259^{* *}$ \\
Training exposure & $0.11135^{\mathrm{NS}}$ \\
Experience in fishing & $-0.12164^{\mathrm{NS}}$ \\
Information source utilization & $0.12787^{\mathrm{NS}}$ \\
Marketing Orientation & $0.00325^{\mathrm{NS}}$ \\
Economic motivation & $-0.06753^{\mathrm{NS}}$ \\
Social participation & $0.09824^{\mathrm{NS}}$ \\
Attitude towards environmental concern & $0.38074^{* *}$ \\
Knowledge & $0.06562^{\mathrm{NS}}$ \\
Adoption & $0.19283^{*}$ \\
\hline
\end{tabular}

*Significant at $5 \%$ and **Significant at $1 \%$ level of probability, NS $=$ Non-significant

family size, size of landholding under agriculture, annual income adoption had positive and significant association with the adoption behaviour of the respondents at 5 per cent level of probability. This signifies that the respondents having larger family size, size of landholding under agriculture, annual income and adoption exhibited higher level of fishing incorporating the stupefying measures. It was also found that independent variables viz., age, education, distance of household from the water bodies, training exposure, experience in fishing, information source utilization, marketing orientation, economic motivation, social participation and knowledge had non-significant association with the adoption behaviour of the respondents.

The study highlights that among the three group of ITK practices, the practice using barks of the plants/ trees were highly effective (mean score value $>3.0$ ), the one utilizing roots was effective (mean score value $>2.5$ ) and the ITK incorporating the leaves was found comparatively slightly less effective (mean score value $>2$ ). During the analysis of rationality of the ITKs, the respondents either declared the ITKs as rational or declared irrational on the basis of present scenario and experience. The farmers rated the ITKs between rationality score of 1 to 4 . The ITKs which received score more than 2.5 as mean score were considered as rationale. Of the 17 practices evaluated, 3 were rational $(42.08 \%)$ while the remaining 14 were rejected as irrational (57.92\%). Among the many documented indigenous practices (Table 4), only 3 valid ITKs which were 'rational and highly effective' are hereby explained and discussed with its rationality score, perceived effectiveness index, adoption rate and workability rationale behind its usage.

Adoption and perceived effectiveness of rationale ITKs : Bark used as sedatives : The barks of Milletia pachycarpa, Albizia chinensis Gnetum montanum Markgraf. Zanthoxylum armatum DC., Zanthoxylum nitidum (Roxb) DC. Aesculus assamica Griff., Duabanga grandiflora (Roxb.) Walp, are peeled into small

Table 4. ITKs pertaining to dairy management with scientific rationality, MPEI and their adoption

\begin{tabular}{|c|c|c|c|c|c|}
\hline ITK & Practices & Rational & MPEI & Adoption \% & Remark \\
\hline ITK 1 & $\begin{array}{l}\text { Mashed extracts of barks of trees Milletia pachycarpa or Albizia } \\
\text { chinensis Gnetum montanum Markgraf.Zanthoxylum armatum DC., } \\
\text { Zanthoxylum nitidum (Roxb) DC. Aesculus assamica Griff., Duabanga } \\
\text { grandiflora (Roxb.) Walp,. }\end{array}$ & 3.01 & 2.6 & 78 & $\mathrm{HE}$ \\
\hline ITK 2 & $\begin{array}{l}\text { Juice extracts of the roots of the large climbing shrubs Milletia } \\
\text { pachycarpa Benth., and also Persicaria lapathifolia Linn Delarbre., } \\
\text { Polygonum hydropiper Linn. Milletia extensa Benth.ex Baker. } \\
\text { Derris scandens Benth. Derris robusta Benth. Derris ferruginea Benth. } \\
\text { Pongamia pinnata Pierre. Zanthoxylum nitidum (Roxb) DC. }\end{array}$ & 2.56 & 2.1 & 64 & $\mathrm{HE}$ \\
\hline ITK 3 & $\begin{array}{l}\text { Crushed leaves of Alangium longiflorum, Blumea balsamifera (Linn.) } \\
\text { shrub and the leaves of Spilanthes oleracea Murr., Polygonum } \\
\text { strigosum R.Br, Tephrosia candida DC., Polygonum hydropiper Linn., } \\
\text { Zanthoxylum nitidum(Roxb) DC. }\end{array}$ & 2.48 & 1.9 & 48 & $\mathrm{E}$ \\
\hline
\end{tabular}

*MPEI- Mean perceived effectiveness index; HE-Highly effective; E-Effective; LE-Less effective 
pieces and smashed against rocks or boulders and the extracted juice is poured in stagnant or semi-stagnant pools, slow flowing streams and rivers for sedating the fish. The direction of flow of the stream is often changed or the stream is blocked by a makeshift boulder dam made of stones, pebbles, boulders and soil. This is done so as to slow down the force of water and also for concentrating the efficacy of the sedative ingredients without being washed away or diluted by strong currents. This documented ITK was rated as rational (3.01), perceived as highly effective (2.60) and adopted by 78 per cent of the respondents (Table 4).

Roots used as sedatives: Often as an annual community activity, a huge number of villagers normally gather at the river bank and do collective crushing of the roots of the large climbing shrub Milletia pachycarpa Benth., and also Persicaria lapathifolia Linn Delarbre., Polygonum hydropiper Linn. Milletia extensa Benth.ex Baker. Derris scandens Benth. Derris robusta Benth. Derris ferruginea Benth. Pongamia pinnata Pierre. Zanthoxylum nitidum (Roxb) DC. The juice extract of the crushed roots is used as sedative for fish in traditional fishing. The piled-up roots are smashed against rocks or big trunks of tree/log and the juice extract are then let to flow into water. Fishes are easily sedated and subsequently paralyzed. Then they are collected by hands or nets or baskets. The greater the number of the bundles, the stronger the effect on the fishes. This poison is more toxic than Rupho (Albizia chinensis) and is more commonly used as fish stupefying poison since it is available in groves (Wanglar Alphonsa and Singh, 2017). This particular technology was rated as rational (2.56), perceived as highly effective (2.1) and adopted by 64 per cent of respondents.

Leaves used as sedatives: The crushed leaves of Alangium longiflorum are kept soaked in water overnight or two for fermentation for more intense efficacy. It is then mixed with water, crushed it further and the extract is let to run in the water of the chosen spot. The stupefied fishes are thus collected. The juice is also used for the treatment of scabies and skin itching by applying on the ailing spot (Wanglar Alphonsa and Singh, 2017). Also the silky hairs of the Blumea balsamifera (Linn.) shrub and the leaves of Spilanthes oleracea Murr., Polygonum strigosum R. Br, Tephrosia candida DC., Polygonum hydropiper Linn., Zanthoxylum nitidum (Roxb) DC. are used as fish sedatives by inserting them into the holes of the fish, which irritate them and compel them to come out from the hole. The method using leaves was rated as rational (2.48), perceived as effective (1.9) and adopted by 48 per cent of respondents.

Chemicals present in these plant extracts sedate the fish when it passes through the gills or in some cases ingested (Negi and Kanwal, 2009). The fishes come to the surface and exhibit abnormal behaviors due to may be nervous breakdown and lack of dissolved oxygen. The semi-conscious or fainted fishes are then collected by the tribal fisherman or local people using simple cloth, cast net and put into the basket. The poison has a narcotic and debilitating action on the fish, without killing them. The sporin paralyzes the fish temporarily. At the beginning all fishes are paralyzed, but those that are in deep pools and those that have not been picked up by fishermen were revived.

\section{CONCLUSION}

Blending of ITK with scientific knowledge system is a vital need of the hour for proper and sustainable intensification of agriculture as well as allied activities. Today, many indigenous knowledge systems are at risk of becoming extinct because of rapidly changing natural environments and fast pacing economic, political, and cultural changes on a global scale (Singh and Chauhan, 2010). Therefore, the indigenous traditional knowledge (ITK) system needs to be studied, documented, preserved and used for the benefit of humankind, before it is lost forever. The age-old herbal fish sedatives have served as excellent means of fishing among the tribal fishermen in Manipur since time immemorial. These ichthyotoxic extracts normally prepared from the smashed or pounded roots, bark, leaves, seeds or the whole plant usually do not kill the whole fish stock unlike chemical poisons. In the absence of sophisticated technologies, this crude but time-tested indigenous knowledge has been easy means for securing a bountiful catch of a large quantity of fish with relatively little efforts in the deep remote areas. The whole activity of preparing these extracts and gathering the fish has always been community-based which harboured unity and brotherhood amongst the tribal fishermen. Even though the effects of the poison are intensely effective, they are usually not fatal and irreversible i.e fishes that are washed and rinsed in fresh running water soon revive and gain consciousness, and can return to their pre- 
toxic condition. Because of this, the fishermen would prefer to gather the stunned fish using these kinds of piscicidal plants. There is an urgent need to standardize and document these herbal techniques of capturing fish before they become totally extinct. Decoding the scientific explanations behind these ichthyotoxic extracts would definitely discourage the new generation of fishermen from resorting to electric or dynamiting methods which are highly detrimental to the environment.

\section{CONFLICTS OF INTEREST}

The authors declare that they have no conflicts of interest.

\section{REFERENCES}

Badola, S.P. and Badola, Smita. (1999). Observations on destructive fishing methods and recommendations to protect fish fauna in Garhwal Himalaya, Sustainable Eco System Environ, 165-168.

Bahuguna, S.N; Kumar, A. and Bisht, B. (2005). Alaknanda ki tin pramukh nadiyon me matsya sanrakshan evam prabandhan, (Proc Uttaranchal me Matsyakii ki Bhavi Sambhavnaayen, HNB Garhwal University, Srinagar-Garhwal), 125-127.

Joshi, K.D. (2004). Wanton destruction of fishery resources in upland waters: A case study, In: Fish diversity in Protected Habitats, (Nature Conservators Publication), $8: 249-254$

Kalita, B; Dutta, A. and Choudhury, M. (2007). Herbal fish toxicant used by fishers of Karbi-Anglong district, Assam, Indian J. of Tradi. Knowledge, 6 (2) : 334-336.

Kritzon, C. (2003) Fishing with poisons www.primitiveways.com/ fish_poison.html

Negi, K.S. and Kanwal, K.S. (2009). Plants used as fish toxins in Garhwal region of Uttarakhand Himalaya. Indian J. of Tradi.Knowledge, 8 (4) : 535-538.

Pradhan, K; Pradhan, S. and Yolmo, Z. (2015). Exploring the correlates of indigenous knowledge utilization index in hill ecosystem of West Bengal. Indian Res. J. Ext. Edu. 15 (2) : 55-61.

Shyam, S; Salim and Antony, P.O. (2013). Indigenous technical knowledge (ITK) in capture fisheries: A case study in Vypeen island of Ernakulam district. Discovery Nature, 4, Number 11.

Singh, S.K. and Chauhan, J. (2010). Perceived effectiveness of ITK among livestock owners. Indian Res. J. Ext. Edu., $10(1): 12-15$.

Sundaramari, M. and Ranganathan, T.T. (2003). Indigenous agricultural practices for sustainable farming. Jodhpur, India; Agrobios (India) Publishers.

Van Andel Tinde. (2000). The diverse uses of fish-poison plants in Northwest Guyana. Econ Bot, 54 (4) : 500-512.

Venkatesan, P. and Sundaramari, M. (2014). Scientific rationality, adoption and perceived effectiveness of traditional agricultural practices of cassava in Kolli Hills, India. J. of Root Crops, 40 (2) : 58-65. (Retrieved from http://www.isrc.in/ojs/index.php/ jrc/article/view/204)

Wanglar Alphonsa Moyon and Singh, L. A. (2017). Ichthyotoxic plants of Manipur. Intl. J. of Fauna and Bio. Studies, $4(4): 29-36$.

Warren, D.M. (1991). Using indigenous knowledge in agriculture development; World Bank Discussion Paper No.127, The World Bank, Washington D.C. 58. 